\title{
Developing a molecular method for screening the resistance to a pathogen of tomato plants to contribute to limiting the use of toxic chemicals in soil
}

\author{
M. Aragona ${ }^{1}$, A. Infantino ${ }^{2} \&$ M. Papacchini ${ }^{1}$ \\ ${ }^{I}$ National Institute for Occupational Safety and Prevention \\ (ISPESL-DIPIA), Rome, Italy \\ ${ }^{2}$ Plant Pathology Research Center (CRA-PAV), Rome, Italy
}

\begin{abstract}
Many soil-borne fungal pathogens cause severe diseases of many important crops. Their control is mainly based on the application of toxic chemicals to the soil, thus representing a serious problem for the environment. Pyrenochaeta lycopersici, the cause of the corky root disease of plants both in the field and in the greenhouse, is a well-studied pathogen of tomato plants. The most effective way to resist the disease has been the use of methyl bromide, which is actually banned, while other chemicals are less effective and still toxic for the environment and the users. The identification and utilization of tomato plant cultivars resistant to the disease represents a valid alternative to the use of chemicals. With this objective, the research aimed to develop a molecular method for the early screening of plants resistant to corky root to be used in breeding programs. The method includes the artificial inoculation of the roots of young tomato plants with a virulent $P$. lycopersici isolate expressing the $\beta$ glucuronidase gene, obtained via genetic transformation of a wild fungal isolate. The histochemical assay of infected roots showed that in resistant cultivars the growth of the fungus is limited from the first stage of the infection. By this method it should be possible to discriminate among susceptible and resistant plants based on the quantification of $\beta$-glucuronidase differentially produced in the infected roots of the tomato plant, in 15 days instead of the 40 days needed with the conventional screening test used until now. The high accuracy of this method will improve the screening procedures for the production of resistant plants, allowing a useful reduction in the use of toxic chemicals in the cultivated soils.
\end{abstract}

Keywords: tomato, disease resistance, infested soil, $\beta$-glucuronidase. 


\section{Introduction}

Corky root, caused by Pyrenochaeta lycopersici, is an important soil-borne disease of the tomato plant in Italy. It causes typical corky lesion on the roots, fig. 1, which can determine stunting and wilting of susceptible plants especially when water stressed. The study of the fungal infection process of tomato plant roots and the monitoring of the propagation of $P$. lycopersici in the soil are hampered by the slow growth of the fungus and the difficulties in the isolation procedures. To this aim, the reporter gene gus $A$ coding for $\beta$-glucuronidase (GUS) has been introduced into the fungal nuclear genome. The use of GUS has been extensively employed for studying the penetration and colonization of plant host tissues by fungal pathogens (Papadopoulou et al. [1], Bae and Knudsen [2]). In addition, in order to monitor the fungal growth in plants, here we report the use of a GUS-based method for qualitative and quantitative assessments of the resistance of tomato plant genotypes employed in breeding programs.

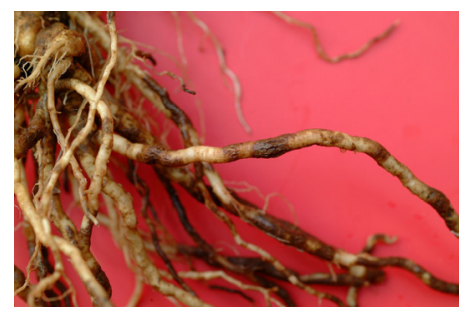

Figure 1: Tomato plant roots naturally infected with Pyrenochaeta lycopersici.

\section{Materials and methods}

\subsection{Genetic transformation of Pyrenochaeta lycopersici}

P. lycopersici ISPaVe ER 1211 isolate, used both in the transformation and inoculation experiments, has been isolated from the heavily infected roots of tomato plants cultivated in Italy. The genetic transformation method has already been described by Aragona and Infantino [3]. Briefly, protoplasts have been prepared from the mycelium of $P$. lycopersici by digestion with a lysing solution containing lysing enzymes $(20 \mathrm{mg} / \mathrm{ml}), \beta$-glucuronidase $(10,000 \mathrm{U} / \mathrm{ml})$ and cellulase $(10 \mathrm{mg} / \mathrm{ml})$. The suspension was incubated at $30^{\circ} \mathrm{C}$ with gentle shaking and the protoplast production was followed by microscope observation during the following 2-4 hours. When the production reached the exponential phase (after more than 2 hours digestion) protoplasts were recovered by filtrating the suspension through 100 and $45 \mu \mathrm{m}$ nylon mesh. After centrifugation, the protoplasts were suspended at a density of $10^{7}-10^{8} / 100 \mu$ and immediately used for transformation or stored at $-20^{\circ} \mathrm{C}$ for a few days. For genetic transformation, 
protoplasts were mixed with two plasmid DNAs, pAN7-1 containing the hygromycin B resistance gene hygB and pNOM102 containing the $\beta$ glucuronidase gene uidA, and plated on a selective medium. Resistant colonies appeared in 4-5 days and were transferred on fresh plates, with or without hygromycin, in order to assess the mitotic stability of the transformants. The transformants were screened for $\beta$-glucuronidase production by using the qualitative and quantitative assay described below on the mycelial extracts.

\subsection{Pathogenicity tests}

Two different tests have been performed. First of all ten cultivars of tomato plants have been artificially inoculated with the ER 1211 strain, following the conventional method described by Infantino and Pucci [4]. Six of them were selected for their differential reaction to $P$. lycopersici, three showed a susceptible reaction after artificial inoculation with the fungus (Corbarino, Monalbo and Eraldo 4), while the other three cultivars were defined resistant to corky root (Moboglan, Deve Peel and LA2531). Then these six were tested for their behavior against the wild type strain ER-1211 and a GUS ${ }^{+}$transformant by a "rapid" pathogenicity assay as follows: the pregerminated seedlings of the tomato plant varieties were planted in pots with vermiculite and watered with a balanced nutrient solution. At the second leaf stage young plants were inoculated by dipping the roots in a homogenate of the fungus for a few seconds, then transplanted in the same pots and maintained in a greenhouse until the GUS assay was performed.

\subsection{GUS assay in planta}

\subsubsection{Histochemical staining}

The histochemical analysis of susceptible and resistant tomato plant genotypes artificially inoculated with the selected $\mathrm{GUS}^{+}$transformant was performed on roots collected at different time points (3,9 and 15 days post-inoculation) and stained overnight at $37^{\circ} \mathrm{C}$ in a $1 \mathrm{mM}$ X-Gluc (5-bromo-4-chloro-3-indolyl- $\beta$-Dglucuronic acid) solution (Jefferson [5]).

\subsubsection{Qualitative assay}

A rapid qualitative assay was performed on inoculated and non inoculated plants after the roots were washed, surface sterilized and homogenized in GUS extraction buffer by using MUG (4-methylumbelliferyl- $\beta$-D-glucuronide) as the substrate for $\beta$-glucuronidase (GUS), as described by Jefferson [5]. Briefly, the roots were homogenized in $2 \mathrm{ml}$ GUS extraction buffer $\left(50 \mathrm{mM} \mathrm{NaPO} \mathrm{pH}_{7.0}\right.$, $10 \mathrm{mM} \beta$-mercaptoethanol, 10mM NaEDTA, 0.1\% sodium lauryl sarcosine, $0.1 \%$ Triton $\mathrm{X}-100)$ and $10 \mu \mathrm{l}$ of the extracts were mixed with $250 \mu \mathrm{l}$ assay buffer ( $1 \mathrm{mM} \mathrm{MUG}$ in extraction buffer). The tubes were incubated at $37^{\circ} \mathrm{C}$ for 60 min during which $50 \mu \mathrm{l}$ aliquots were taken at intervals of $15 \mathrm{~min}$ and stopped by addition of $25 \mu \mathrm{l} 1 \mathrm{M} \mathrm{Na}_{2} \mathrm{CO}_{3}$. 


\subsubsection{Quantitative measurements of GUS activity}

The root extracts, obtained as described for qualitative assay, were analyzed for protein content by the Bradford method [6]. An amount of 0,1-10 $\mu$ g of proteins was added to $100 \mu \mathrm{l}$ assay buffer, for each sample, and after incubation at $37^{\circ} \mathrm{C}$ for 0-60 min the reactions were terminated by adding $900 \mu \mathrm{l} 0.2 \mathrm{M} \mathrm{Na}_{2} \mathrm{CO}_{3}$ and were stored at $4{ }^{\circ} \mathrm{C}$. Quantitative estimation of $\beta$-glucuronidase activity of the extracts was performed by fluorometry and expressed as nanomoles of 4methylumbelliferone (MU) produced per minute per milligram of protein. The experiments were repeated three times.

\section{Results and discussion}

\subsection{Transformation and characterization of transformants}

A genetic transformation system has been developed for P. lycopersici. Protoplasts obtained from the mycelium of a highly virulent isolate were cotransformed with plasmids pNOM102 containing the $\beta$-glucuronidase gene and pAN7-1 for hygromycin resistance, in the presence of PEG. P. lycopersici does not possess endogenous $\beta$-glucuronidase activity so that we were able to select the transformants, with a frequency of $1-2 / \mu \mathrm{g}$ of DNA, after the first selection based on hygromycin resistance. Thirty-one hygromycin resistant transformants were selected and, when tested for GUS activity by the rapid qualitative MUG assay, twelve of them resulted positive, giving a co-transformation frequency of about $40 \%$. One of the transformants obtained showed unaltered morphology and growth rate on PDA plates, compared with the untransformed strain, and has been chosen for further characterization.

Southern analysis and hybridization using the GUS gene as a probe showed that the integration of the transforming vector (pNOM102) had occurred in tandem copies in multiple sites of the genome. After artificial inoculation of roots of a susceptible tomato plant cultivar, the virulence was comparable between the transformed and the untransformed strains.

Quantitative estimation of $\beta$-glucuronidase production has been performed from mycelial extracts by fluorometry. A high yield of $\beta$-glucuronidase has been produced for the selected transformant: $905 \mathrm{nmol} \mathrm{min}^{-1} \mathrm{mg}_{\text {protein }}{ }^{-1}$, expressed as the amount of 4-methylumbelliferone (MU) produced. This high GUS activity was probably due to the multiple vector copies integrated into the genome, without compromising the pathogenicity and the physiological traits in both the transformants.

\subsection{Analysis of the infection process}

Corky root disease in tomato plants has a quite slow progression, because of the slow growth of $P$. lycopersici. Pathogenicity test usually performed to test the resistance of tomato plant cultivars requires about 40 days after the artificial inoculation of roots with a virulent fungal isolate. The use of the GUS transformant associated with a rapid inoculation test allowed to follow the 
infection process since the early stages of disease. Histochemical detection of the pathogen has been set for one susceptible and one resistant tomato plant cultivar, named Corbarino and Moboglan respectively. After artificial infection of roots with the GUS ${ }^{+}$transformant and ER-1211 as control, three plants for each thesis were collected at 3,9 and 15 days post-inoculation (dpi). The roots have been sterilized by $\mathrm{NaOCl}$ in order to eliminate the mycelium adhering on the root surface and were stained overnight at $37^{\circ} \mathrm{C}$ in a $1 \mathrm{mM} \mathrm{X}$-Gluc solution. GUS histochemical staining of mycelium in infected tomato plant roots was easily visualized both macroscopically and by microscopy. At 3 dpi small necrotic areas, distributed as spots on the tap root, were evident on the susceptible roots, fig. 2. At $15 \mathrm{dpi}$, the differences between the susceptible and the resistant genotype were clear: the larger root of the susceptible cultivar was entirely colonized by the $\mathrm{GUS}^{+}$isolate and destroyed, showing the typical lesions of the corky root disease, while roots of the resistant cultivar were still weakly colonized, fig. 2. In handmade longitudinal sections the histochemical staining showed that the fungus remained restricted to the root cortex and did not invade the central tissues, data not shown.

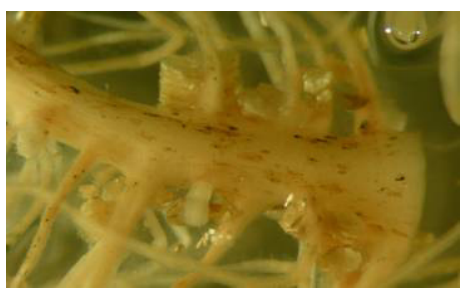

a

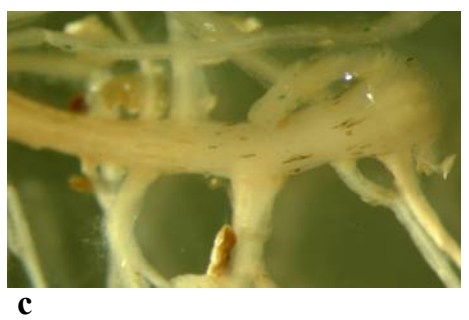

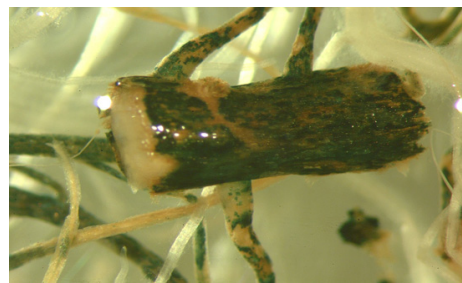

b

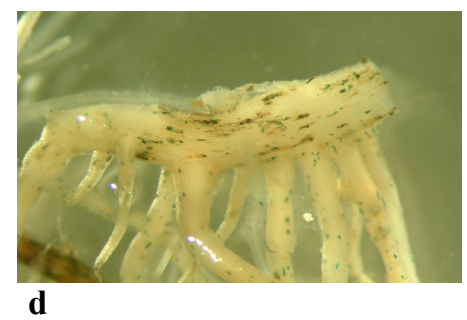

Figure 2: Tomato plant roots artificially infected with Pyrenochaeta lycopersici GUS+; a: Corbarino (susceptible) at $3 \mathrm{dpi}$; b: Corbarino at $15 \mathrm{dpi}$; c: Moboglan (resistant) at $3 \mathrm{dpi}$; d: Moboglan at $15 \mathrm{dpi}$.

The histochemical assay gave a relevant, but only a qualitative, picture of the progression of infection. To quantify $P$. lycopersici spread inside the tomato plant tissues, roots of three susceptible and three resistant tomato plant varieties inoculated with the GUS ${ }^{+}$isolate were harvested at 3,9 and 15 dpi to be analyzed for MU production. First of all the six cultivars have been analyzed by a qualitative assay based on the fluorescence produced when MUG is converted in MU in the presence of $\beta$-glucuronidase. All the extracts from roots of the three 
susceptible cultivars were intensively fluorescent under UV light, while two of three resistant ones showed no fluorescence and one resistant cultivar was only weakly fluorescent. Quantitative estimation of $\beta$-glucuronidase present at the root level in the six tomato plant cultivars was the next step. At present preliminary analysis of quantitative measure by fluorimetry has been performed only on one susceptible (Corbarino) and one resistant (Moboglan) genotype. An amount of $45.1 \pm 2.52$ and $1.94 \pm 0.11 \mathrm{nmol}$ MU min- $1 \mathrm{mg}$ protein- 1 has been obtained in the susceptible and resistant genotype respectively. The analysis of all the tomato plant genotypes should give a more complete picture of the behavior of $P$. lycopersici in resistant and susceptible cultivars and at the same time the reaction of different tomato plant cultivars against the pathogen.

\section{Conclusions}

The high sensitivity of GUS-based method allows in planta detection and quantitative analysis. It could represent a potential instrument in early screening for resistance to corky root of tomato plants that at present is time consuming, needing at least 40 days after artificial inoculation before evaluating the infected plants. From the first results a positive correlation was found between GUS activity and biomass of in vitro-grown $P$. lycopersici, therefore GUS activity may be used for following fungal growth in plants and for selection of plants resistant to corky root to be used in breeding programs.

This system could also represents a model for other soil-transmitted diseases, for which the use of resistant plants is, actually, the unique alternative to the application of toxic chemicals to the cultivated soil.

\section{References}

[1] Papadopoulou, K.K., Kavroulakis, N., Tourn, M. \& Aggelou, I., Use of $\beta$ glucuronidase activity to quantify the growth of Fusarium oxysporum f.sp. radicis-lycopersici during infection of tomato. Journal of Phytopathology, 153, pp. 325-332, 2005.

[2] Bae, Y-S. \& Knudsen, G.R., Cotransformation of Trichoderma harzianum with $\beta$-glucuronidase and green fluorescent protein genes provides a useful tool for monitoring fungal growth and activity in natural soils, Applied and Environmental Microbiology, 66(2), pp. 810-815, 2000.

[3] Aragona, M. \& Infantino, A., Expression profiling of tomato response to Pyrenochaeta lycopersici infection, Acta Horticulturae (in press).

[4] Infantino, A. \& Pucci, N., A PCR-based assay for the detection and identification of Pyrenochaeta lycopersici, European Journal of Plant Pathology, 112, pp. 337-347, 2005.

[5] Jefferson, R.A., The GUS gene fusion system, Plant Molecular Biology Report, 5, pp. 387-405, 1987.

[6] Bradford, M.M., A rapid and sensitive method for the quantitation of microgram quantities of protein utilizing the principle of protein-dye binding, Analytical Biochemistry, 72, pp. 248-254. 